\title{
LA CALIDAD Y LA PRODUCTIVIDAD EN LA UNIVERSIDAD ESTATAL
}

\author{
M. A. Raúl Arrarte Mera*
}

\begin{abstract}
RESUMEN
Las Universidades, en especial las estatales, desempeñan un rol de suma importancia en la formación de los'RR. HH.; en la creación, desarrollo, transferencia y adaptación de tecnologías. De suerte que, lo que ellas hagan en el futuro, para responder adecuadamente a los requerimientos de la sociedad moderna, se constituyen en un imperativo estratégico para el desarrollo nacional.

Las Universidades son reconocidas como instrumentos de desarrollo de ciudades, regiones y países y están consideradas como un factor clave para incrementar la competitividad y calidad de vida de sus ciudadanos. El desafio para las instituciones de Educación Superior es el de enfrentar. un mundo en el cual los sistemas productivos están en permanente transformación. Los que abren nuevas perspectivas para la docencia y la investigación universitarias.
\end{abstract}

\section{EVOLUCIÓN HISTÓRICA}

Competitividad y eficiencia eran dos palabras poco utilizadas en la gestión universitaria de nuestro país que se desenvolvía hasta la década de los noventa, después del vendaval terrorista, en un medio ambiente sin turbulencias en el cual el financiamiento estatal estaba asegurado y la competencia se encontraba limitada al mercado interno.

El reconocimiento de la globalización, de una economía altamente competitiva que enfatiza la calidad total. Luego, la reducción del Estado y la adopción del concepto de subsidiaridad lo llevó a recortar su participación en la Educación Superior y a destinar sus escasos recursos a la Educación Básica. En la práctica esto significó dejar la Educación Superior a la iniciativa privada. (Pacheco Vásquez, 1997).

Surgió así un nuevo tipo de Universidad: la universidad particular, concebida como empresa de servicios educativos y defendida elocuentemente por los representantes del neoliberalismo en el Perú, que vieron a la Educación Superior como una actividad económica cualquiera. El 9 de noviembre de 1996, el Gobierno promulgó el Decreto Legislativo N. ${ }^{\circ}$ 882, estableciendo condiciones y garantías para promover la inversión privada en educación con el fin de modernizar el sistema educativo y ampliar la oferta a todos los niveles.

Este marco de referencia, legaliza la propiedad de las instituciones

* Docente Auxiliar de la Facultad de Ciencias Contables. 
educativas particulares, es decir garantiza el derecho de propiedad de las entidades promotoras.

Para la UNESCO:"En la actualidad dificilmente existe algún pais capaz de financiar un sistema comprensivo de Educación Superior es exclusivamente, con recursos públicos. Visto el estado de la economía en varias regiones del mundo, y los persistentes déficit presupuestarios a nivel local y de los Estados, parece improbable que dicha tendencia pueda revertirse en los próximos años." Una verdadera clarinada.

Los elementos que caracterizan este nuevo entorno:

\section{Diferenciación institucional}

Existen Universidades públicas y privadas con regimenes legales diferenciados.

\section{Masificación de la matricula.}

En 1943 San Marcos recibió 359 alumnos, en 1990,1994; 5549 en 1999 y 5343 en el 2000.

\section{Restricción de Recursos}

No es un problema típico peruano, ha afectado de manera crónica a países del África y gran parte de Asia. Ya no existe la bonanza de tiempos pasados. Esto es válido para Japón, pero también para Canadá.

\section{Incremento de la competencia entre instituciones de la Educación Superior}

Según los registros estadísticos de la ANR (Asamblea Nacional de Rectores), el mes de febrero del 2002, existian en el país 33 Universidades Estatales y 45 Universidades Privadas. Además de la presencia de Institutos de Educación Superior para profesionales de mando medio con estudios de 3 años.

\section{Diversificación de la demanda}

Ya no sólo los jóvenes recién egresados de la enseñanza secundaria aspiran a recibir una educación de nivel superior. Ahora también están los profesionales que buscan ampliar o mejorar sus conocimientos y destrezas, personas que desean o deben cambiar de ocupación, funcionarios $y$ trabajadores que buscan acreditar y certificar su experiencia laboral y organizaciones interesadas en obtener servicios docentes en función de sus propios programas de capacitación.

\section{Transición hacia economias basadas en el conocimiento}

"El mayor de los cambios se ha producido en el campo del conocimiento y el mayor desafío es el de la educación ya que en el futuro inmediato se requerirá de personas diferentes educadas de distinta manera que como se hace hoy en dia, con capacidades adecuadas para enfrentar y resolver situaciones nuevas en un entorno rápidamente cambiante".(Peter Drucker, 1994).

La búsqueda permanente de nuevos conocimientos y de nuevas técnicas dentro de una concepción unificadora del mundo, plantea la necesidad de revisar los esquemas tradicionales de la educación superior, su misión, su metodologia, y en general, toda la estructura del sistema educativo.

\section{Globalización de los mercados y Competitividad}

La creciente internacionalización de los mercados laborales en el ámbito profesional y técnico, exige que los diplomas otorgados en un país puedan ser reconocidos en los demás, de manera de facilitar la movilidad de la propia fuerza laboral más altamente calificada y de 
atraer a estudiantes del extranjero por lo cual la evaluación de la calidad de las instituciones y programas de Educación Superior se ha transformado en un imperativo de alcance mundial.

\section{El cambio en la orientación de la valoración social}

Nuestra sociedad ha experimentado cambios en sus valores: la calidad de los productos, la competencia, la responsabilidad pública, la transparencia y la eficiencia. El usuario asume en propiedad su rol de "cliente" y exige bienes y servicios de calidad, incluyendo una educación que satisfaga sus expectativas.

Existe una creciente presión social sobre la calidad de los servicios universitarios: docencia, investigación, transferencia tecnológica, etc. Los cambios y transformaciones del entorno de la educación superior repercuten de manera directa en los sistemas de gestión, dirección y organización de las instituciones de educación superior.

\section{CALIDAD Y EDUCACIÓN SUPE- RIOR}

El término "calidad" en latín significa "cualidad, manera de ser"; su significado castellano es "propiedad o conjunto de propiedades inherentes a una cosa, que permiten apreciarla como igual, mejor o peor, que las restantes de su especien.

Las definiciones de calidad han sufrido un proceso evolutivo que va, desde aspectos puramente cuantitativos relacionados con la calidad técnica de un producto, hasta un enfoque acorde a las necesidades del usuario que satisfaga sus requerimientos.

Desde la perspectiva de las políticas educativas mundiales, la calidad de la educación queda determinada por la capacidad que tienen las instituciones para preparar al individuo, destinatario de la educación, de tal modo que pueda adaptarse y contribuir al crecimiento, desarrollo económico y social, mediante su incorporación al mercado laboral.

La educación de calidad es la que logra resultados que permitan el progreso y la modernización. Elevar la calidad es entonces encontrar los medios necesarios para el logro de los fines. Midiendo los resultados, se adecuan los medios pertinentes.

La docencia es de calidad si logra desarrollar competencias en el educando. Entendiendo como tal a la capacidad de actuar desde lo que la persona es, con sus valores y actitudes; haciendo algo con lo que sabe. Para que la docencia sea calificada de calidad, debe además, satisfacer las demandas sociales en cuanto a formación profesional, que no es sólo una mera acumulación de conocimientos, sino debe ser un proceso de aprendizaje constante que:

expanda las potencialidades del individuo.

Que logre su integración al complejo entorno cultural, productivo y social que caracteriza a la actual sociedad globalizada.

\section{PRODUCTIVIDAD Y COMPETI- TIVIDAD}

- Productividad. Es la relación entre los productos y los insumos necesarios para su producción. Es una medida de la eficiencia del empleo de los recursos para generar bienes $y$ servicios, que compara cuánto producimos con los recursos que utilizamos para producirlo. 
- Pero la productividad y eficiencia que se exige a las universidades no sólo tiene una dimensión económica, la Universidad actúa como un servicio público y por ende, no sólo es regulada por el mercado o los precios, sino que se enfrenta al desafío de la "eficiencia social" ; capacidad de satisfacer, sin limitaciones ni discriminaciones de tipo alguno, la creciente demanda con una educación masiva de calidad.

\section{IV. ¿QUÉ HACER ANTE ESTAS PERSPECTIVAS?}

- Lo que nos lleva a plantear que el sistema de formación profesional no sólo su curriculo debe estar orientado hacia una estructura basada en competencias, sino que dicha práctica coincida con las necesidades "estratégicas* de las empresas, desde su ámbito de mercado, y pasando por la base tecnológica, organizativa $\mathbf{y}$ cultural. (Mertens, 2000).

- Por tanto, la calidad de la docencia como visión global e integral es el resultado de un conjunto de procesos que conducen a su obtención, de manera que para lograr la calidad se deba analizar los procesos intermedios 0 coadyuvantes, en diversos grados de los aprendizajes y no sólo su resultado final. Porque el sistema educativo constituye la oferta formativa básica al servicio del conjunto de la población.

- Muchos creen que la educación ha funcionado a manera de una caja negra, cuya opacidad impide saber qué ocurre en su interior. En el momento actual, dicha imagen resulta ampliamente insatisfactoria, siendo numerosas las voces que reclaman una mayor transparencia. Pues conociendo el grado de logro de sus objetivos, será fundamental para hacer mejor uso de los recursos disponibles y para tomar las decisiones más adecuadas.

- En este contexto, surge la Acreditación como un proceso por medio del cual, un programa o entidad educativa, brinda información sobre sus objetivos y logros a un organismo externo que evalúa y juzga, de manera independiente, dicha información para poder hacer una declaración pública sobre el valor o calidad del programa o entidad educativa. La acreditación constituye una constancia de credibilidad por parte de la sociedad y del público demandante de los servicios educativos.

- Por tanto, la Universidad Pública, sólo tiene una alternativa: adaptarse al mercado o morir en el intento. Pero iniciémoslo ya. Fácil es vender paraguas, el problema es hacer llover. ¿Lo intentaremos en el 2004?

\section{BIBLIOGRAFÍA}

Espinoza, O. Manual de Auto evaluación de Instituciones de Educación Superior: Pautas y Procedimientos. Centro Inter universitario de Desarrollo (CINDA), 1994.

Mertens, Leonardo. 2000. La Gestión por Competencia Laboral en la Empresay la Formación Profesional. Organización de los Estados Iberoamericanos para la Educación, la Ciencia y la Cultura.

Pacheco Vâsquez, Amelia. Universidad de Lima. Fondo de Desarrollo Editorial, 1997. 